\title{
Biomechanical and Tribological Aspects of Orthopaedic Implants
}

\author{
Irena Gotman
}

\begin{abstract}
Orthopaedic and dental implant treatments have allowed to enhance the quality of life of millions of patients. Total hip/knee arthroplasty is a surgical replacement of the hip/knee joint with an artificial prosthesis. The aim of joint replacement surgery is to relieve pain improve function, often for sufferers of osteoarthritis, which affects around a third of people aged over fifty. Nowadays, total hip and knee replacement (THR) surgeries are considered routine procedures with generally excellent outcomes. Given the increasing life expectancy of the world population, however, many patients will require revision or removal of the artificial joint during their lifetime. The most common cause of failure of hip and knee replacements is mechanical instability secondary to wear of the articulating components. Thus, tribological and biomechanical aspects of joint arthroplasty are of specific interest in addressing the needs of younger, more active patients. The most significant improvements in the longevity of artificial joints have been achieved through the introduction of more wear resistant bearing surfaces. These innovations, however, brought about new tribocorrosion phenomena, such as fretting corrosion at the modular junctions of hip implants. Stiffness mismatch between the prosthesis components, non-physiological stress transfer and uneven implant-bone stress distribution are all involved in premature failure of hip arthroplasty. The development of more durable hip and knee prostheses requires a comprehensive understanding of biomechanics and tribocorrosion of implant materials. Some of these insights can also be applied to the design and development of dental implants.
\end{abstract}

Keywords Total joint replacements $\cdot$ Low friction arthroplasty $\cdot$ Stress shielding $\cdot$ Wear of polyethylene $\cdot$ Hard-on-hard articulations $\cdot$ Fretting wear $\cdot$ Tribocorrosion

I. Gotman ( $\varangle)$

Department of Mechanical Engineering, ORT Braude College, Karmiel, Israel e-mail: irenag@braude.ac.il 


\section{Introduction to Orthopaedic and Dental Implantable Devices}

Orthopaedic and dental implants are surgical components that replace or interface with the bone. The most important implantable orthopaedic devices are total joint replacements, primarily total hip (THR) and total knee replacements (TKR), Fig. 1(left).

The aim of joint replacement surgical procedure (arthroplasty) is to relieve pain, improve function, and enhance quality of life, often for sufferers of osteoarthritis, which affects around a third of people aged over 50. Worldwide, more than one million THR surgeries and about two million TKR surgeries are performed every year, approximately $50 \%$ of which are done in the US. The rapidly aging population and a high prevalence of degenerative bone conditions in the elderly drive the demand for joint replacements even higher. According to American Academy of Orthopaedic Surgeons, the number of primary THRs in the US is projected to reach 635,000 in the year 2030 (171\% increase vs. year 2014) and 1.23 million in the year $2060(330 \%$ increase). Similarly, the projections for primary TKR are 1.28 million in the year 2030 (189\% increase vs. year 2014) and 60 million in the year 2060 (382\% increase).

Total joint arthroplasty is considered one of the most successful surgical interventions performed today. The reported survivorship after 15 years is above $90 \%$ for total hip replacements [1] and ranges between 82 and $98 \%$ for total knee replacements [2]. Despite this success, failures of joint replacements do occur, in which case the patient is required to undergo a revision surgery to replace the failed implant. In fact, the number of revision procedures is increasing faster than the number of primary arthroplasties. The projections of American Academy of Orthopaedic Surgeons for the US are 72,000 revision THRs (142\% increase vs. year 2014) and 120,000 revision TKRs (190\% increase) in the year 2030 and 110,000 revision THRs (219\% increase vs. year 2014) and 253,000 revision TKRs (400\% rise) in the year 2060. The rising rates
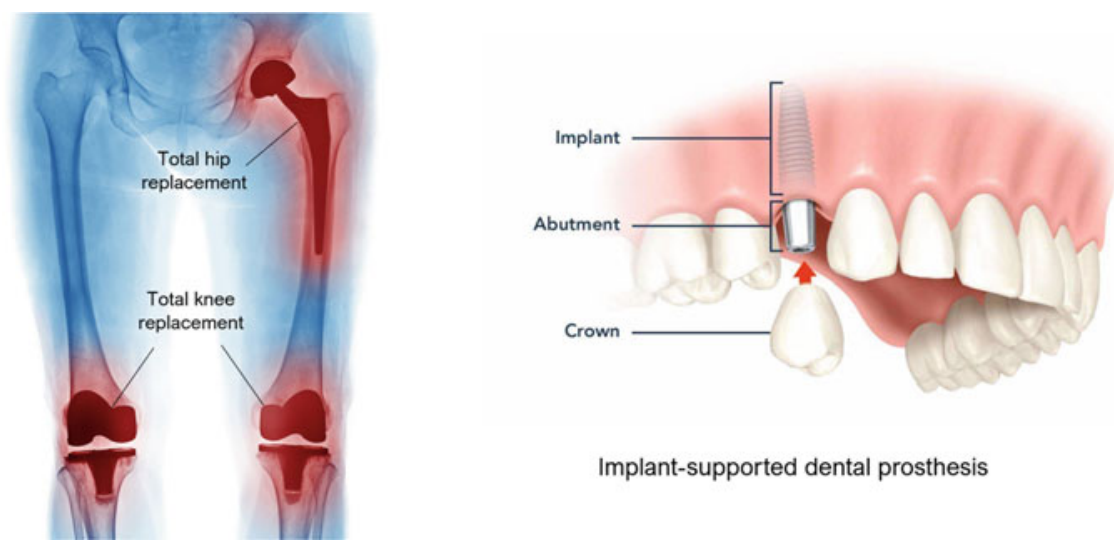

Implant-supported dental prosthesis

Fig. 1 Total joint replacements (left) and implant-supported dental prosthesis (right) 
of failure are not surprising given the fact that patients currently receiving THR/TKR are $\sim 20 \%$ heavier, more physically active, and live more than $25 \%$ longer compared with several decades ago. According to the latest study, approximately $42 \%$ of THRs will not last more than 25 years [3, 4]. This means that some artificial joints will need to be replaced at least once during a patient's lifetime. For younger patients (under 60 years of age), the lifetime risk of revision is around 30\%, with the highest revision rates reported for males between the ages of 50-55 [5]. These clinical data indicate that the ultimate goal of joint arthroplasty-long-term pain-free function for the rest of the patient's life-has not yet been achieved.

Another important class of bone-interfacing prostheses are dental implants, Fig. 1(right). A dental (or endosseous) implant is a surgical replacement of the tooth root that interfaces with the with the bone of the jaw or skull to support a dental prosthetic (e.g. crown or bridge). The main objective of implant supported dental restoration is the permanent replacement of missing teeth. Every year, more than 800,000 dental implants are placed in the United States and more than 1.8 million in the European Union. As population is aging, the demand for dental implants will rise significantly in the next decade. Projection models suggest that among the US adults missing teeth, the prevalence of dental implant use could reach as high as $23 \%$ by the year 2026 [6]. Dental implants are designed to last a lifetime and have, according to different sources, a success rate of over $90 \%$ at $10-15$ years followup [7]. However, failures do happen, especially in medically compromised patient population. It has been suggested that failure patterns and mechanisms behind bone loss around dental implants have much in common with joint replacements, and that biomechanical under- or overloading and synergy between friction, wear and corrosion are responsible for the majority of dental and orthopaedic implant system failures [8-10]. Therefore, a total hip replacement will be used throughout this paper as it is a representative example of an orthopaedic implant and because the knowledge from the discipline of orthopedics can be applied to oral implants.

\section{Tribology of Total Hip Replacement}

\subsection{Charnley Low Friction Arthroplasty}

The hip is one of the body's largest weight-bearing joints. This geometrically simple "ball-in-socket" joint consists of the head (top of the thigh bone, or femur) articulating inside the acetabular socket of the pelvis. The layer of articular cartilage covering the bone surfaces lubricated by the synovial fluid provides the joint with exceptional tribological properties. Total hip arthroplasty consists of replacing both the acetabulum and the femoral head with artificial components. The first total hip replacements were performed by Wiles (1938) and McKee (1951) [11]. In those early designs, both bearing surfaces (acetabular cup and femoral head) were made of stainless steel and were fixed to the bone with screws and bolts. These historical implants experienced 
high incidence of early failure associated with the component loosening, typically of the acetabular cup. The unsatisfactory clinical performance was primarily due to elevated friction, jamming and wear within the bearings. It turned out that the main limitation of the early THR designs was that they mimicked normal hip joint anatomy. Large femoral heads coupled with inconsistent manufacturing tolerances generated high frictional torque (turning force) on the articulating surfaces leading to high shear stresses and loosening at the acetabular cup-bone interface.

Realization of the tribological nature of failure of early hip replacement designs brought Sir John Charnley to introduce his revolutionary concept of "low-friction arthroplasty" (LFA) [12]. LFA follows the principle of low-frictional torque based on the largest possible difference between the radius of the femoral head and that of the outer aspect of the acetabular component [13]. Charnley and his colleagues concluded that in order to minimize frictional torque and protect the cup-bone interface, the head diameter should be not greater than half of the external diameter of the cup. Consequently, the head diameter of THR was reduced from the earlier used 41.5-22.2 $\mathrm{mm}$, less than half anatomical femoral head diameter (48-55 $\mathrm{mm}$ on the average). Charnley also recognized that in addition to the low frictional torque design, it is important that the acetabular cup material had a low friction coefficient against the material of the femoral head (stainless steel in Charnley prosthesis). The first material used was a self-lubricating polymer polytetrafluoroethylene (PTFE). PTFE sockets, however, wore out disappointingly fast causing "intense foreign body reaction" to wear debris and gross destruction of bone. The next polymeric material used-ultra-high molecular weight polyethylene (UHMWPE) [14] proved much more successful. UHMWPE had excellent wear resistance, low friction and high impact strength, and no problems were observed with metal-on-UHMWPE (M-PE) bearings in the early years post-implantation. Thus, the biomechanical concept of low friction arthroplasty combined with the use of a low-wear acetabular cup material (UHMW polyethylene) started a new era in joint replacement surgery. Very soon, a more biocompatible and corrosion resistant cobalt-chromium alloy $(\mathrm{CoCr})$ came to replace stainless steel in the femoral component of Charnley prostheses. From then on, arthroplasty has known considerable evolution, but metal-on-UHMWPE (CoCr$\mathrm{PE}$ ) articulation remains the gold standard for artificial hips and other artificial joints, including the knee and shoulder. It is definitely Sir John Charnley to be credited with advancing our understanding of tribological effects as they apply in orthopaedics, and the significance of friction, wear and lubrication of implant materials for their longevity and function, and particularly the body's reaction to the particulate debris produced as a result of implant wear [15].

Another breakthrough made by John Charnley was the introduction of a selfcuring acrylic resin (bone cement) as a grouting agent to secure the implant components to bone. The cement is injected as a dough-like mass and hardens around the implant to ensure its anchorage in the bone [16]. The use of bone cement allowed for the firm fixation of hip replacements unachievable with the previously used screws and bolts. Charnley cemented THA rapidly gained widespread popularity and became one of the most successful orthopaedic procedures with reported survivorship rates greater than $90 \%$ at $15-20$ years. In young, physically active patients, however, failure 
rates were significantly higher. The main mode of failure was aseptic loosening (loss of fixation) of one or both implant components, secondary to periprosthetic osteolysis-resorption of bone surrounding the implant [17, 18]. At the time, osteolysis was thought to be caused by biological reaction to bone cement described as "cement disease". This led to the erroneous conclusion that the problem of aseptic loosening can be solved if the use of bone cement is avoided. Consequently, the innovative concept of cementless fixation was developed. In the cementless approach, implant components are stabilized within the bone by bone ingrowth into the porous surface layer or by bone ongrowth onto the textured surface. The material of choice for cementless prostheses are titanium alloys (mostly Ti6Al4V) due to their superior biomechanical compatibility: Ti6Al4V is capable of osseointegration (establishing direct contact with bone) and has a low modulus of elasticity, half that of $\mathrm{CoCr}$ alloy (110 vs. 230 GPa) [19]. The latter is important for minimizing periprosthetic bone resorption due to stress shielding caused by stiffness mismatch between the implant and the bone (elastic modulus of $\sim 20 \mathrm{GPa}$ ) [20]. Against early expectations, cementless fixation did not eliminate the problem of aseptic loosening of hip replacements and the outcomes were no better than with cemented THA.

\subsection{Wear of Polyethylene-The Main Culprit of Aseptic Loosening}

Once it became clear that not "cement disease" was the problem, the proposition that aseptic loosening is related to particulate wear debris from the UHMWPE acetabular component was put forward. The hard metal femoral head can produce wear of the polyethylene surface during articulation through both abrasive and adhesive mechanisms. Positive asperities on the hard counterface can abrade the polyethylene surface, which is relatively softer, producing abrasive wear debris. Friction between the articulating surfaces shears off particles, producing adhesive wear debris. Hard particles present in the joint space (cement, metal, bone) can enter between the articulating surfaces, embed in the polyethylene and abrade the metallic counterface"third body" wear mechanism. In total knee replacements, the dominant form of wear is delamination of polyethylene which occurs as a result of cyclic compressive-tensile loading that leads to subsurface cracking. Wear particles migrate into tissues and are phagocytosed by macrophages which become activated and release pro-inflammatory cytokines that stimulate bone resorption (osteolysis) around the implant leading to prosthesis loosening [21-23]. Typically, billions of submicron UHMWPE wear particles (average diameter of $0.3-0.5 \mu \mathrm{m}$ ) per year are released into periprosthetic fluids. Two main factors affecting the volumetric wear of UHMW polyethylene are diameter and material of the femoral head that articulates against the polyethylene. $\mathrm{CoCr}$ alloy is a metal traditionally used for the femoral head. Meanwhile, titanium alloys exhibit poor tribological behavior under abrasive and adhesive wear and should not be used for manufacturing femoral heads. Titanium is much softer than $\mathrm{CoCr}$ and is 
easily scratched by hard "third body" particles that intrude between the articulating surfaces which results in increased friction and abrasive wear of the polyethylene. For CoCr heads articulating against UHMWPE, larger heads are associated with greater volumetric wear of polyethylene and high revision rates. The popular $28 \mathrm{~mm}$ diameter is a compromise between wear performance and risk for dislocation of the implant.

\section{Alternative Bearing Surfaces}

Since the inflammatory response to wear debris was established as the main cause of aseptic loosening, efforts at extending joint replacement longevity have focused primarily on development of more wear resistant bearing surfaces. Two major directions included ( $i$ ) improving the quality of UHMWPE and (ii) avoiding the use of polyethylene bearing altogether. Alternatively, attempts were made to improve the wear resistance of metallic components by providing them with a hard, wear resistant surface.

Prior to being introduced into clinical practice, new artificial joint materials must be submitted to realistic preclinical tests. The tribological performance of novel THA bearing couples is tested in hip joint simulators designed to mimic the biomechanics of hip joint in a simulated physiological environment. Despite the reported discrepancies between in vitro simulation results and wear data from explanted devices, joint simulators are instrumental in predicting clinical wear performance of new bearing surfaces and identifying the risk of clinically relevant wear [24].

\subsection{Cross-Linked Polyethylene}

Radiation cross-linking significantly decreased the wear rate of UHMWPE against CoCr in simulation studies, Fig. 2.

In total hip arthroplasty, this has translated into better long-term outcomes and a significant reduction in the rate of revision for younger patients [25]. Furthermore, highly cross-linked polyethylene may allow use of large-diameter femoral heads without concern about increased polyethylene wear [26]. The biomechanical rationale for using large-diameter femoral heads is that they allow for a greater range of motion and limit the risk of dislocation by increasing jump distance-distance the head has to "jump" before leaving the acetabular cup [27]. For total knee arthroplasty, however, clinical evidence has been inconclusive, and no distinctive improvement was observed when highly cross-linked polyethylene (HXLPE) was used compared to conventional UHMWPE [28-30]. This could be attributed to distinct biomechanical environments and different relative contributions of polyethylene wear mechanisms in the two types of joints: adhesive and abrasive wear in the hip versus fatigue wear and delamination in the knee. In addition, the reduced fatigue strength and toughness 


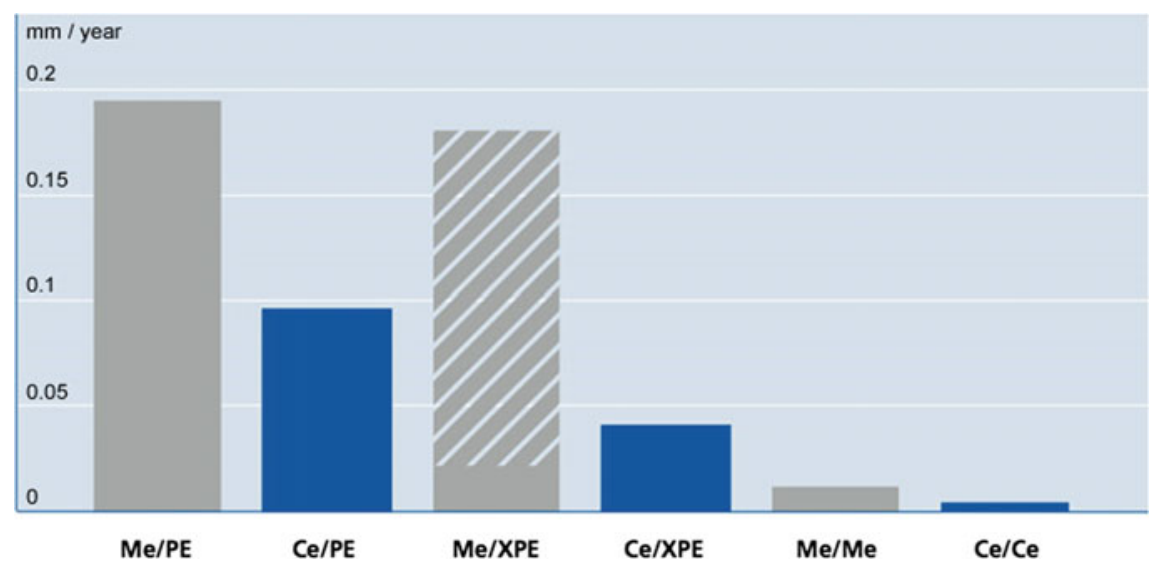

Fig. 2 In vivo linear wear rates of different bearing couples.: Me-metal, PU-UHMW polyethylene, $\mathrm{Ce}$-ceramic, XPE—cross-linked polyethylene. https://www.ceramtec.com/biolox/clinicalexperience/wear-osteolysis/

of cross-linked polyethylene may cause the cracking of HXLPE knee replacement components.

\subsection{Ceramic-on-Polyethylene Articulation}

The wear of polyethylene acetabular components has been further reduced by replacing the femoral head material from the $\mathrm{CoCr}$ metal to a ceramic. The first ceramic used was aluminum oxide (alumina). Alumina is oxidation resistant, biocompatible, very hard and scratch resistant. Furthermore, the fine grain structure allows alumina to be polished to a very low surface roughness $(\mathrm{Ra}<0.05 \mu \mathrm{m})$ resulting in reduced wear of the polyethylene countersurface. In addition, the high wettability of alumina positively affects the lubricating film thus decreasing the coefficient of friction [31]. Due to the brittle nature of alumina, however, a few (but potentially devastating) fracture failures of the early ceramic heads (Biolox ${ }^{\circledR}$ forte, CeramTec, $\mathrm{GmbH}$ ) were reported. To reduce the risk of brittle fracture of femoral heads, an alternative ceramic material-yttria stabilized zirconia (Y-TZP) was introduced. YTZP is a metastable material that exhibits an extremely high (for a ceramic) fracture toughness due to a unique transformation toughening mechanism. High fracture toughness combined with excellent tribological behavior against polyethylene made zirconia femoral heads very popular in the last decade of the past century. It turned out, however, that when exposed to body fluids, the metastable tetragonal phase may transform to the stable monoclinic structure [32, 33]. This aging process occurs in vivo on the surface of zirconia heads, leading to their roughening and microcracking. The problem became apparent in the year 2000 when an unusually large 
amount of failures was reported following a change in the manufacturing process of zirconia heads. In 2001, the company St. Gobain Desmarquest (Vincennes, France) issued a voluntary recall, and the use of zirconia femoral heads in hip arthroplasty came to an end.

An important step towards enhancing the resistance of ceramic femoral heads to brittle fracture was the introduction of zirconia-toughened alumina - a composite ceramic (Biolox delta) whose fracture toughness is twice that of Biolox forte [34]. The volumetric wear of polyethylene acetabular cups articulating against ceramic femoral heads is several times lower than that of their metal-on-polyethylene counterparts, Fig. 2. The absence of allergic reaction to alumina makes ceramic-on-polyethylene articulation especially suitable for patients suffering from immune hypersensitivity to metals such as nickel, chromium and cobalt.

\subsection{Hard-on-Hard Articulations}

Notwithstanding the improved wear resistance of cross-linked polyethylene, the most spectacular reductions in volumetric wear of articulating joints (by one-two orders of magnitude) are achieved with hard-on-hard (metal-on-metal and ceramicon-ceramic) bearings, eliminating altogether the soft polyethylene component, Fig. 2.

\subsubsection{Ceramic-on-Ceramic Bearings}

Ceramic-on-ceramic (CoC) articulations exhibit by far the lowest wear rates and are considered a viable option for young, active patients. Excellent mid-term clinical outcomes are reported for modern $\mathrm{CoC}$ hip replacements using zirconiatoughened alumina (Biolox delta), and component fractures are extremely rare [35, 36]. One well-recognized and annoying complication of ceramic-on-ceramic THA is squeaking - a high pitched, audible sound that occurs during movement, often related to a specific activity $[37,38]$. The reported incidence of squeaking in CoC THA lies between $0.5 \%$ and $>20 \%$. A likely cause of squeaking is adverse tribological conditions caused by the loss of fluid film lubrication and high friction between the ceramic components. Friction generates forced vibrations that cause the metallic parts to resonate and convert vibrational energy into an audible noise. The incidence of squeaking is strongly affected by implant- and patient-specific factors.

\subsubsection{Metal-on-Metal Bearings}

Metal-on-metal (MoM) total hip arthroplasty almost totally abandoned in the mid1970's in favor of Charnley's metal-on-polyethylene THA, made its comeback in the very beginning of the twenty-first century [39-41]. By that time, it became clear that 
the failures of fist generation metal-on-metal implants were not due to the bearing surface material but were mainly caused by design errors and inadequate manufacturing. Survivorship analysis of hip replacements implanted between 1965 and 1973 revealed a surprisingly great longevity among some of the original all-metal designs. At long-term follow-up, the wear of the long-lived metal-on-metal McKee-Farrar prostheses was by at least one order of magnitude smaller compared to the metalon-polyethylene Charnley prostheses. Novel CoCr-on-CoCr devices designed with the standard small femoral head diameter (22 and $28 \mathrm{~mm}$ ) exhibited very low wear rates in hip simulator tests, only slightly higher than those of ceramic-on-ceramic couples. At the same time, they possessed an obvious advantage of not being brittle. An important observation from the simulation tests was that more effective fluid film lubrication and correspondingly low wear rates were achieved with larger diameter femoral heads. Based on these results, large diameter $(\geq 36 \mathrm{~mm})$ MoM articulations were developed and quickly gained a big share of the market, both in the USA (approx. 30\% in 2006-2007) and worldwide. It took only a few years to realize that MoM THA was associated with higher revision rates and lower patient satisfaction. In addition to the well-known phenomenon of aseptic loosening), a new mode of failure was observed-adverse local tissue reaction (ALTR) [42, 43]. ALTR included periprosthetic soft tissue inflammation, soft tissue necrosis, and pseudotumor formation. Some patients were asymptomatic but those presenting with pain and elevated metal blood levels had to be revised.

The final blow for metal-on-metal designs came in 2010 when DePuy, J\&J's orthopaedic branch voluntarily recalled its ASR MoM hip system due to an unacceptably high failure rate $(\sim 13 \%$ after 5 years) [44]. The use of metal-on-metal devices declined rapidly to less than $1 \%$ of all the THR systems being implanted today. The analysis of failed implants revealed that wear particles from MoM articulations are approximately $50 \mathrm{~nm}$ in size, much smaller than the $0.3-0.5 \mu \mathrm{m}$ UHMWPE debris particles. Thus, despite the low volumetric wear of MoM bearings, the actual number of released particles is considerably higher than for conventional metal-onPE bearings. Moreover, these metallic nanoparticles are more biologically active and corrode rapidly in the body fluids releasing large amounts of potentially toxic cobalt and chromium ions. The unfavorable outcomes of large diameter metal-on-metal hip replacements are the result of their complex and not well-understood tribology. From the biomechanical and tribological point of view, MoM articulations were found to be extremely unforgiving to positioning and manufacturing mistakes: slight deviations from the optimal alignment, sphericity and radial clearance could lead to adverse lubrication conditions and excessive wear. To date, there are no FDAapproved metal-on-metal total hip replacement devices marketed for use in the US, the only available options being ceramic-on-ceramic, ceramic-on-polyethylene and metal-on-polyethylene bearings. 


\section{Bearing Materials in Total Knee Replacement}

In total knee arthroplasty (TKR), bearing surface options have been much more limited. Practically all state-of-the-art knee replacements use a $\mathrm{CoCr}$ alloy femoral component articulating on polyethylene. The knee joint has a complex nonconformal geometry and is subjected to high contact stresses. Polyethylene is sufficiently compliant to accommodate stress concentration caused by misalignment or surfaceto-surface contact of asperities. The rigid nature of ceramics makes ceramic-onceramic articulation much less forgiving of surface irregularities and slight malposition thus leading to increased risk of brittle fracture. Therefore, transferring the benefits of excellent tribological properties of ceramics to the complex geometry of knee prostheses remains challenging. At the present time, all-ceramic knee endoprosthesis is not a feasible option. Several TKA designs having a ceramic femoral component articulating on polyethylene are available for clinical use or are under clinical trial [45-47]. These devices represent a promising alternative for patients with a known hypersensitivity to metals, but it is still early to draw conclusions regarding their long-term outcomes in terms of longevity, wear damage and incidence of brittle fracture.

\section{Surface-Modified Bearing Materials}

The desired alternative to existing articulating materials for joint implants would combine the fracture toughness of metals with the wear performance of ceramics [48]. One approach for achieving this is to deposit or overlay a ceramic coating onto a metallic substrate. The bond created between the deposited coating and the substrate is only physical (rather than chemical) resulting in relatively weak coating adhesion. Given the significantly different mechanical properties of the ceramic film and the underlying metal, adhesive failure between the two materials occur under load or during articulation. Diamond like carbon (DLC) and titanium nitride (TiN) are the most extensively studied wear resistant coatings for artificial joints. Despite their high hardness and excellent biocompatibility, delamination and spalling of such coatings has been observed in clinical trials and some wear simulation tests. Insufficient adhesion and inadequate load bearing capacity of the underlying softer metallic substrate are believed to be the major obstacles on the way to successful implementation of hard coatings into clinical practice [48]. It is believed that these shortcomings of externally applied ceramic layers can be alleviated by diffusional surface hardening - reactively diffusing a non-metallic element into the substrate at elevated temperatures thus transforming the surface from metal to ceramic.

Oxidized zirconium (OXINIUM, Smith \& Nephew Orthopaedics) was developed for orthopedic applications to provide improvements over $\mathrm{CoCr}$ alloy for resistance to roughening, frictional behavior, and biocompatibility without the mechanical limitations of brittle monolithic ceramics [49]. The ceramic surface is formed 
by heating a zirconium alloy in air to allow oxygen to diffuse into the substrate and to transform the metal surface to zirconium oxide (zirconia) ceramic. Despite the consistently lower wear of polyethylene components articulating against the ceramic surfaced OXINIUM in knee and hip joint simulator tests, clinical studies have shown no statistically significant differences in mid-term implant survivorship between OXINIUM and CoCr components [50-52]. Additional research is needed for the clinical performance of OXINIUM to better understand long-term outcomes. Meanwhile, OXINIUM contains no detectable nickel or chromium, which makes such implants a safer choice for patients with metal allergies.

\section{Fretting Wear Damage of Total Joint Replacements}

\subsection{Modular Connections of Hip Prostheses}

In early hip replacement devices, the femoral stem and head were produced as a single-piece, monolithic component-a so-called monobloc design, Fig. 3a. Nowadays, almost all hip joints are modular and consist of a separate femoral head that fits on the stem, Fig. 3b, c. The reliable joining of modular components of total joint replacements is based on the concept of a Morse taper, i.e. that of the cone in the cone $[53,54]$. The two components of the Morse taper form a firm fit that relies on friction and mechanical interlocking. Modularity provides many advantages, such as greater intraoperative flexibility allowing the surgeon to restore the patient's anatomy and
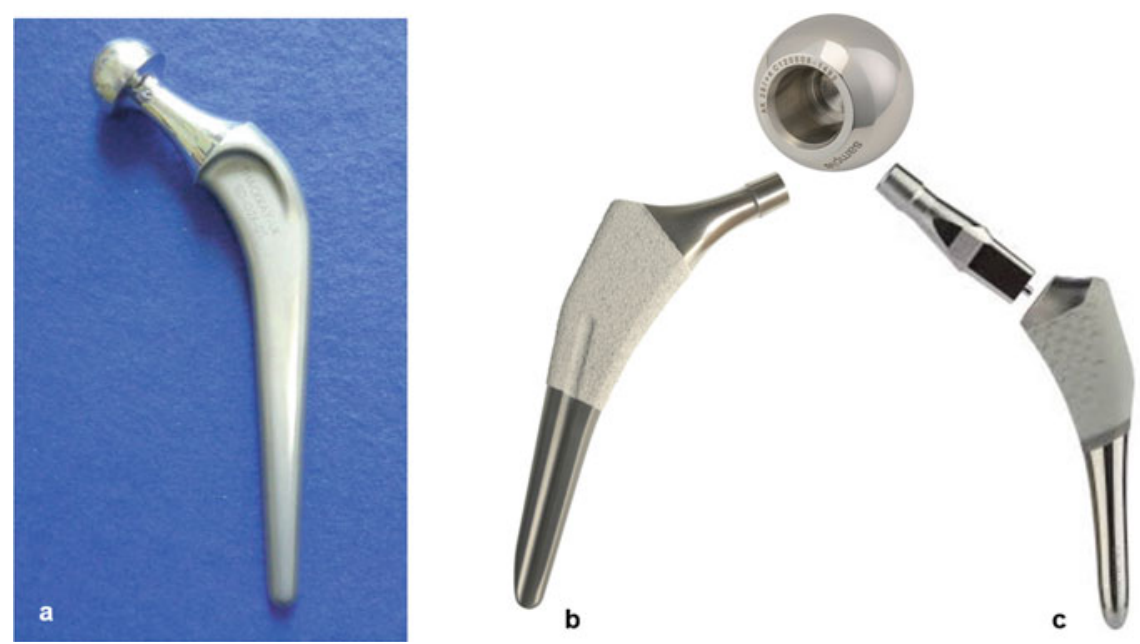

Fig. 3 Different designs of femoral components of total hip replacement: monoblock (Charnley) (a) and modular (b, c): b-monolithic stem, c-dual-taper stem 
to adjust leg length, decreased implant inventory and potential ease of revision by exchanging only the failed component. Furthermore, modularity allows the combination of head and stem made of different materials with specific properties thus optimizing the clinical performance of the whole assembly. For example, a stem from titanium alloy that is most suitable for cementless fixation but has an inadequate wear resistance can be combined with a hard, wear resistant Co alloy or ceramic head.

Despite its benefits, the modular design has been associated with higher revision rates due to adverse tissue reaction, neck fracture and femoral head disassociation. Modularity creates additional mechanical junctions (neck-head and neck stem interfaces having a crevice-like geometry) that become weak points where micromotion and wear can occur [55]. The hip joint is subject to cyclic stresses from gait loading amounting to more than one million cycles a year. As a result of cyclic loading, a low amplitude oscillating relative motion occurs at the taper junction of femoral components made of dissimilar materials and having different rigidity. This leads to the tribological process of fretting causing surface damage of the fitting contact surfaces. The process is often referred to as "mechanically assisted crevice corrosion"(MACC) and can be briefly described as follows [56-59], Fig. 4a-d. Rubbing between the taper surfaces under stress leads to mechanical disruption of the protective oxide film and corrosion followed by rapid regeneration of the oxide layer (repassivation). This is accompanied by oxygen consumption, metal ion release and hydrolysis, and voltage drop. As the mechanical damage to the oxide is continuously repeated, oxygen in the crevice is depleted while the liberated hydrogen ions acidify the fluid to the point where repassivation becomes impossible. Given that the corrosion resistance
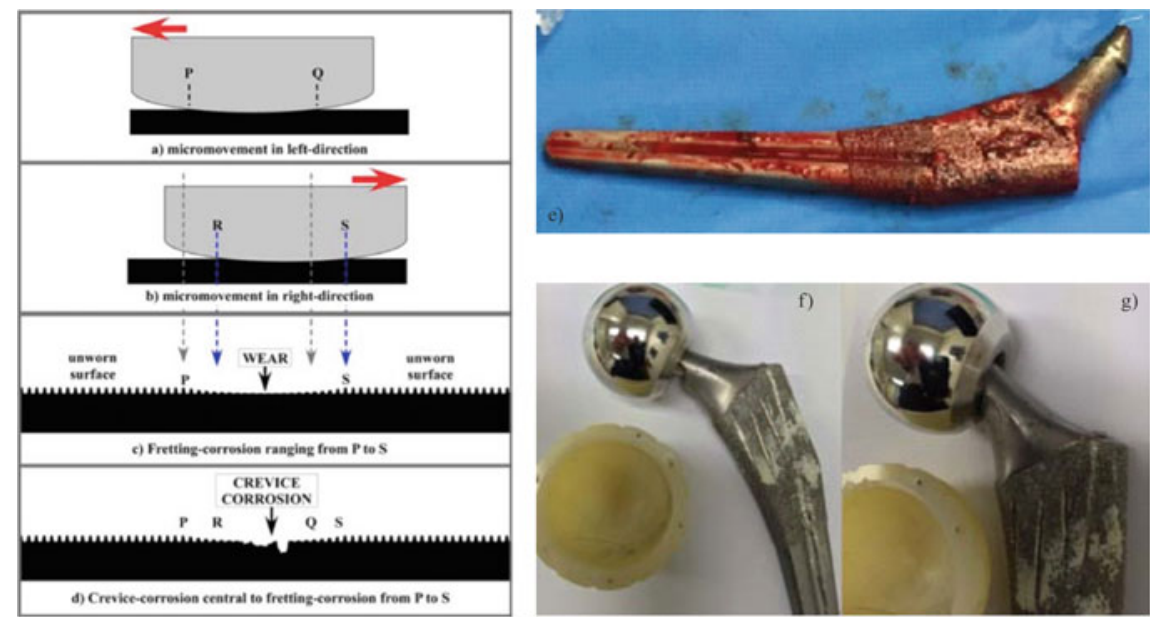

Fig. 4 a-d Schematic of mechanically assisted crevice corrosion (MACC); e retrieved Accolade stem with marked fretting wear of the neck taper; $\mathbf{f}$ retrieved Accolade stem with instability and dissociation of the head-neck junction. Reproduced from P. Walker et al., Reconstructive Review 2016, September; 6(3):13-18 
of both cobalt and titanium alloys relies on passivity, the inability to rebuild the passive oxide film results in active corrosion. An additional feature of MACC is hydrogen gas accumulation below the modular neck and hydrogen embrittlement on the surface of titanium components $[60,61]$. MACC at the femoral head-neck interface of modular hip replacements is commonly referred to as trunnionosis.

Wear debris and metal ions produced at taper junctions can lead to elevated blood metal ion concentrations and adverse local tissue reactions. The histological appearance of periprosthetic tissues surrounding corroded trunnions is similar to tissues surrounding failed hip replacements with metal-on-metal bearings. Some patients will remain asymptomatic; others will develop adverse clinical symptoms that require revision: necrosis, pseudotumors, pain, etc. In heavy patients, cases of catastrophic fatigue fracture of titanium male stem tapers initiated at notch-like irregularities of the fretted surface were reported $[62,63]$.

Several modular hip systems are available on the market, differing in design and femoral stem/neck/head material. As discussed above, the head is typically made of the wear-resistant cobalt-chromium alloy or ceramic whereas the stem can be either cobalt-chromium or titanium alloy. The stem can be monolithic (one-piece design), Fig. 3b, or can have an exchangeable neck (dual-taper stem), Fig. 3c. In the latter case, an additional stem/neck interface is introduced which only increases the concern regarding the occurrence of mechanically assisted crevice corrosion. Ti alloys are the common material choice for cementless stems due to their superior osseoconductivity and low stiffness preventing bone resorption secondary to stressshielding. In this respect, beta-titanium alloys whose elastic modulus is significantly lower than that of the standard Ti-6Al-4V alloy are most favorable candidate materials [64]. However, combining beta-titanium with the high-modulus $\mathrm{Co}-\mathrm{Cr}$ alloy components has proven disastrous and led to several major Hip Replacement recalls. The beta-titanium involved is a proprietary Ti-12Mo-6Zr-2Fe (TMZF $\left.{ }^{\circledR}\right)$ alloy having the elastic modulus of around $75 \mathrm{GPa}$ that was developed by Stryker Orthopaedics.

When a monolithic TMZF stem (Accolade I stem design) was used in combination with a Co-Cr alloy head (LFIT V40) supposed to minimize the risk of dislocation, high incidence of failures due to taper wear and adverse local tissue reaction was reported [65-68]. The patients experienced pain and restricted motion requiring a revision surgery. In some cases, tapers were damaged to such a significant level that head dissociation from the stem occurred. Examples of such gross stem taper failure (GTF) and head disassociation are shown in Fig. 4e-g. It is hypothesized that micromotion and fretting corrosion at the taper junction results in the widening of the gap between the head and the neck which allows the head to turn and move on the stem. The harder Co-Cr head abrades the softer titanium alloy neck to such an extent that the head can easily disassociate from the stem. Importantly, GTF has occurred recurrently with stems made of the low-modulus TMZF alloy, very rarely with stems from the standard Ti-6Al-4V alloy and never with the high modulus Co$\mathrm{Cr}$ alloy stems suggesting the influence of the material stiffness. Indeed, numerical modelling has shown that the deformation and micromotion at the Co-Cr head-stem taper interface was significantly larger for the TMZF-alloy stem compared to the $\mathrm{CoCr}$ and even to Ti-6Al-4V alloy stems. The phenomenon of head disassociation 
was most often observed with large diameter Co-Cr heads (36 $\mathrm{mm}$ and larger) and these were voluntarily recalled by the manufacturer in 2016 . Other femoral head sizes, as well as ceramic heads remain on the market however problems with the device continue to be of concern as failures in implant sizes outside of the recall are being reported. The Accolade I stem made of the low-modulus TMZF beta titanium alloy was never recalled but its use declined rapidly. In 2012 Stryker replaced Accolade I stem with the standard Ti-6Al-4V alloy stem (Accolade II).

The most well-known case of tribocorrosion of modular hip replacements is the failure of dual-taper Rejuvenate and ABG II stems launched by Stryker Orthopaedics in 2009 [69-72]. Both designs combined a low-modulus TMZF femoral stem and an exchangeable cobalt-chromium alloy neck. Since $\mathrm{Co}-\mathrm{Cr}$ is harder and stiffer than titanium, it was suggested that this would allow safer and long-term use of the modular neck. The femoral heads were either $\mathrm{Co}-\mathrm{Cr}$ or ceramic articulating on a UHMW polyethylene acetabular cup. Extremely high revisions rates secondary to tribocorrosion at the taper connection were reported for both designs, reaching, for Rejuvenate stem, $65 \%$ three years post-implantation. Due to these unacceptable failure rates and the ensuing FDA investigation, Stryker was forced to issue a voluntary recall of both products in 2012. Similarly to the case of Accolade II, the culprit in the failure of the dual-taper mixed-metal stem was the low elastic modulus of the TMZF alloy. Following the recall of the Rejuvenate and ABG II, Stryker discontinued the use of the low-stiffness beta-titanium and replaced it with the standard Ti-6Al-4V alloy. Current recommendations regarding modular hip replacements include avoiding femoral stems with low flexural rigidity and reducing the number of modular junctions, e.g. by using fixed neck stems. Also, substituting $\mathrm{Co}-\mathrm{Cr}$ alloy heads with the chemically inert ceramic heads is expected to reduce MACC since corrosion processes will only occur on the metallic stem taper and will not be accelerated by galvanic coupling with a dissimilar metal $[73,74]$. From the biomechanical point of view, smaller diameter heads are typically reported to produce less fretting damage since they generate smaller head-neck moment arm and correspondingly smaller torsional forces at the head-neck taper junction $[75,76]$. The use of small diameter heads (36 $\mathrm{mm}$ and less), however, is associated with an increased risk of dislocation of hip replacement and is not willingly accepted by orthopaedic surgeons.

It follows from the above discussion that even if all the guidelines are followed, tribocorrosion at modular junctions of orthopaedic and dental implants exposed to cyclic loading cannot be fully eliminated. To overcome the problem of head-neck taper degradation, different surface engineering approaches are being investigated. One possibility is to coat a titanium alloy stem taper with a hard, wear-resistant film. The results of in vitro evaluation of TiN and TiN/AlN coatings suggest that these coatings provide superior fretting and fretting corrosion resistance to the tapered interfaces of the Co-Cr-Mo and Ti-6Al-4V alloy components [77-79]. Increasing the interfacial bond strength between the coating and the substrate could improve the fretting and corrosion resistance even more. 


\subsection{Stem-Cement Interface}

Another joint replacement zone prone to tribocorrosion is the stem-cement interface of cemented prostheses [80-83]. Under physiological loading, this interface experiences a low amplitude oscillatory micromotion. During relative sliding, hard radiopacifier particles (e.g., $\mathrm{ZrO}_{2}$ ) within the cement abrade the polished surface of the femoral stem and induce a tribocorrosive interaction. The effect is most pronounced for titanium alloy stems that experience larger flexural deflections and are more easily abraded than the stiffer and harder $\mathrm{CoCr}$ stems [84]. Fretting wear damage results in the formation of gaps/crevices between the cement mantle and the titanium stem leading to crevice corrosion of the metallic surface. Both the surface damage and the immunological reaction to released particles and ions compromise the stem stability and may lead to premature failure of the cemented joint prosthesis. Similarly to the taper junctions of modular implants, the low elastic modulus of titanium here is a drawback rather than an advantage. Flexural deflections of femoral stems lead to the cracking of the cement mantle and debonding at cement-stem interface, and both phenomena are much more pronounced for the low-stiffness titanium stems. These biomechanical and tribocorrosion problems make Ti alloy stems a much less popular option for cemented hip replacements. Although cemented Ti alloy stems are still available on the market, it is believed by many that the use of titanium stems in cemented THA should be abandoned [85].

\section{Tribocorrosion in Dental Implants}

Despite high success rates, 5-11\% of implant-supported dental restorations fail within 10-15 years and must be removed [86]. The dominant failure mode of dental implants is peri-implantitis (inflammation of tissues surrounding the implant) and the associated loss of supporting bone. Tribocorrosion at internal connections between the prosthesis parts (implant, abutment and crown) and at implant-bone interface is among the major contributors to peri-implantitis [87-90]. The implant and the abutment are made of titanium or titanium alloy, whereas the crown is usually made of porcelain or zirconia ceramic. Despite very precise machining, there always is a microgap between the implant and the prosthetic connector. During mastication, micromotion occurs at the implant-abutment and abutment-crown interface leading to fretting and crevice corrosion. The situation is obviously similar to mechanically assisted crevice corrosion at taper connections of total hip replacements. The released degradation products (metal ions and metal oxide particles) initiate inflammatory tissue response that can eventually result in peri-implant bone loss. Furthermore, material loss enlarges the microgap between the abutment and the implant allowing for rapid gap colonization by oral microorganisms and subsequent bacterial infection. The combined action of microbiological, mechanical and tribocorrosion factors 
promotes peri-implantitis and the associated bone loss eventually leading to implant failure.

\section{Summary}

With the growing demand for orthopaedic and dental implants and expectations of longer device lifetimes for the younger patients, wear and corrosion of articulating surfaces and modular junctions of these implantable devices are a prime concern. Aside from the patient's activity and physiological state, the biotribological performance of a prosthesis depends on the mechanical design and the materials used (metals, ceramics, polymers). Despite the substantial improvements achieved in both directions, the ultimate goal of total joint replacements-long-term pain-free function for the rest of the patient's life-has not yet been achieved. Currently there are gaps in our understanding of biomechanics and wear behavior of medical implants. Closing these gaps will help guide future research in this field and improve the longevity of orthopaedic and dental implantable devices.

\section{References}

1. Ferguson RJ, Palmer AJR, Taylor A, Porter ML, Malchau H, Glyn-Jones S (2018) Hip replacement. Lancet 392:1662-1671

2. Price AJ, Alvand A, Troelsen A, Katz JN, Hooper G, Gray A, Carr A, Beard D (2018) Knee replacement. Lancet 392:1672-1682

3. Cook R, Davidson P, Martin R (on behalf of NIHR Dissemination Centre) (2019) More than 50\% of hip replacements appear to last 25 years. Journal BMJ 367:15681

4. Evans JT, Evans JP, Walker RW, Blom AW, Whitehouse MR, Sayers A (2019) How long does a hip replacement last? A systematic review and meta-analysis of case series and national registry reports with more than 15 years of follow-up. Lancet 393:647-654

5. Bayliss LE, Culliford D, Monk AP, Glyn-Jones S, Prieto-Alhambra D, Judge A, Cooper C, Carr AJ, Arden NK, Beard DJ, Price AJ (2017) The effect of patient age at intervention on risk of implant revision after total replacement of the hip or knee: a population-based cohort study. Lancet 389:1424-1430

6. Elani HW, Starr JR, Da Silva JD, Gallucci GO (2018) Trends in dental implant use in the U.S., 1999-2016, and projections to 2026. J Dental Res 97(13):1424-1430

7. Moraschini V, da C. Poubel LA, Ferreira VF, dos SP Barboza E (2015) Evaluation of survival and success rates of dental implants reported in longitudinal studies with a follow-up period of at least 10 years: a systematic review. Int J Oral Maxillofac Surg 44:377-388

8. Albrektsson T, Becker W, Coli P, Jemt T, Mölne J, Sennerby L (2019) Bone loss around oral and orthopedic implants: an immunologically based condition. Clin Implant Dentistry Related Res 21(4):786-795

9. Coli P, Sennerby L (2019) Is peri-implant probing causing over-diagnosis and over-treatment of dental implants? J Clin Med 8(8):1123. https://doi.org/10.3390/jcm8081123

10. Souza JCM, Henriques M, Teughels W, Ponthiaux P, Celis JP, Rocha LA (2015) Wear and corrosion interactions on titanium in oral environment: literature review. J Bio- Tribo-Corrosion 1(13). https://doi.org/10.1007/s40735-015-0013-0 
11. Gomez PF, Morcuende JA (2005) Early attempts at hip arthroplasty-1700s to 1950s. Iowa Orthop J 25:25-29

12. Wroblewski BM, Siney PD, Fleming PA (2006) The Charnley Hip replacement -43 years of clinical success. Acta Chirurgiae Orthopaedicae et Traumatologiae Cechoslovaca 73(1):6-9

13. Wroblewski BM, Siney PD, Fleming PA (2009) The principle of low frictional torque in the Charnley total hip replacement. J Bone Joint Sur Br Vol 91-B:855-858

14. Sobieraj MC, Rimnac CM (2009) Ultra high molecular weight polyethylene: mechanics, morphology, and clinical behavior. J Mech Behav Biomed Mater 2(5):433-443

15. Sonntag R, Beckmann NA, Reinders J, Kretzer JP (2015) Materials for total joint arthroplastybiotribology of potential bearings. Imperial College Press, London, pp 15-40

16. Vaishya R, Chauhan M, Vaish A (2013) Bone Cement. J Clin Orthop Trauma 4(4):157-163

17. Iannotti JP, Balderston RA, Booth RE, Rothmann RH, Cohn JC, Pickens G (1986) Aseptic loosening after total hip arthroplasty. J Arthroplasty 1:99-103

18. Sundfeldt M, Carlsson LV, Johansson CB, Thomsen P, Gretzer C (2006) Aseptic loosening, not only a question of wear: a review of different theories. J Acta Orthop 77(2):177-197

19. Geetha M, Singh AK, Asokamani R, Gogia AK (2009) Ti based biomaterials, the ultimate choice for orthopaedic implants-a review. Prog Mater Sci 54:397-425

20. Sumner DR (2015) Long-term implant fixation and stress-shielding in total hip replacement. J Biomech 48(5):797-800

21. Abu-Amer Y, Darwech I, Clohisy JC (2007) Aseptic loosening of total joint replacements: mechanisms underlying osteolysis and potential therapies. Arthritis Res Therapy 9(1):6

22. Harris WH (1994) Osteolysis and particle disease in hip replacement. A review. Acta Orthop Scand 65:113-123

23. Wooley PH, Schwarz EM (2004) Aseptic loosening. Gene Ther 11:402-407

24. Medley JB (2016) Can physical joint simulators be used to anticipate clinical wear problems of new joint replacement implants prior to market release? Proc Inst Mech Eng Part H J Eng Med 230(5):347-358

25. Dumbleton JH, D'Antonio JA, Manley MT, Capello WN, Wang A (2006) The basis for a second-generation highly cross-linked UHMWPE. Clin Orthop Relat Res 453:265-271

26. Allepuz A, Havelin L, Barber T, Sedrakyan A, Graves S, Bordini B, Hoeffel D, Cafri G, Paxton E (2014) Effect of femoral head size on metal-on-HXLPE hip arthroplasty outcome in a combined analysis of six national and regional registries. J Bone Joint Surg 96(1):12-18

27. Banerjee S, Pivec R, Issa K, Kapadia BH, Khanuja HS, Mont MA (2014) Large-diameter femoral heads in total hip arthroplasty: an evidence-based review. Am J Orthop (Belle Mead, N.J.) 43(11):506-512

28. Brown TA, van Citters DW, Berry DJ, Abdel M (2017) The use of highly crosslinked polyethylene in total knee arthroplasty. Bone Joint J 99B(8):996-1002

29. Wilhelm SK, Henrichsen JL, Siljander M, Moore D, Karadsheh M (2018) Polyethylene in total knee arthroplasty: where are we now? J Orthop Surg 23(6):1-7

30. de Steiger RN, Muratoglu O, Lorimer M, Cuthbert AR, Graves SE (2015) Lower prosthesisspecific 10-year revision rate with crosslinked than with non-crosslinked polyethylene in primary total knee arthroplasty. Acta Orthop 86(6):721-727

31. Cash D, Khanduja V (2014) The case for ceramic-on-polyethylene as the preferred bearing for a young adult hip replacement. HIP Int 24(5):421-427

32. Habermann B, Ewald W, Rauschmann M, Zichner L, Kurth AA (2006) Fracture of ceramic heads in total hip replacement. Arch Orthop Trauma Surg 126:464-470

33. Chevalier J (2006) What future for zirconia as a biomaterial? Biomaterials 27(4):535-543

34. Kurtz SM, Kocagöz S, Arnholt C, Huet R, Ueno M, Walter WL (2014) Advances in zirconia toughened alumina biomaterials for total joint replacement. J Mech Behav Biomed Mater $31: 107-116$

35. Reuven A, Manoudis G, Aoude A, Huk OL, Zukor D, Antoniou J (2014) Clinical and radiological outcome of the newest generation of ceramic-on-ceramic hip arthroplasty in young patients. Adv Orthop Surg. https://doi.org/10.1155/2014/863748 
36. Kuntz M, Usbeck S, Pandorf T, Heros R (2011) Tribology in total hip arthroplasty (Knahr K, ed). Springer, Berlin, pp 25-40

37. Brockett CL, Williams S, Zhongmin J, Isaac GH, Fisher J (2013) Squeaking hip arthroplasties. J Arthrop 28(1):90-97

38. Mai K, Verioti C, Ezzet KA, Copp SN, Walker RH, Colwell Jr CW (2010) Incidence of 'squeaking' after ceramic-on-ceramic total hip arthroplasty. Clin Orthop Relat Res 468(2):413417

39. Triclot $P$ (2011) Metal-on-metal: history, state of the art (2010). Int Orthop 35:201-206

40. Drummond J, Tran P, Fary C (2015) Metal-on-metal hip arthroplasty: a review of adverse reactions and patient management. J Funct Biomater 6(3):486-499

41. Delaunay C, Petit I, Learmonth ID, Oger P, Vendittoli PA (2010) Metal-on-metal bearings total hip arthroplasty: the cobalt and chromium ions release concern. Orthoaed Traumatol Surg Res OTSR 96(8):894-904

42. Matharu GS, Eskelinen A, Judge A, Pandit HG, Murray DW (2018) Acta Orthop 89(3):278-288

43. Engh CA, MacDonald SJ, Sritulanondh S, Korczak A, Naudie D, Engh C (2014) Metal ion levels after metal-on-metal total hip arthroplasty. J Bone Joint Surg 96(6):448-455

44. Fernández-Valencia J, Gallart X, Bori G, Ramiro SG, Combalía A, Riba J (2014) Assessment of patients with a DePuy ASR metal-on-metal hip replacement: results of applying the guidelines of the Spanish Society of Hip surgery in a tertiary referral hospital. Adv Orthop. https://doi. org/10.1155/2014/982523

45. Bergschmidt P, Bader R, Kluess D, Zietz C, Mittelmeier W (2012) The all-ceramic Knee endoprosthesis - the gap between expectation and experience with ceramic implants. Seminars Arthrop 23:262-267

46. Meier E, Gelse K, Trieb K, Pachowsky M, Henning FF, Mauerer A (2016) First clinical study of a novel complete metal-free ceramic total knee replacement system. J Orthop Surg Res 11(21). https://doi.org/10.1186/s13018-016-0352-7

47. Solarino G, Piconi C, De Santis V, Piazzolla A, Moretti B (2017) Ceramic total knee arthroplasty: ready to go? Joints 5(4):224-228

48. Gotman I, Gutmanas EY, Hunter G (2017) Comprehensive biomaterials II (Ducheyne P, ed). Elsevier, Amsterdam, pp 165-203

49. Hunter G, Jones WM, Spector M (2005) Total knee arthroplasty (Bellemans J, Ries MD, Victor JMK, ed). Springer-Verlag, Heidelberg, pp 371-377

50. Vertullo CJ, Lewis PL, Graves S, Kelly L, Lorimer M, Myers P (2017) Twelve-year outcomes of an oxinium total knee replacement compared with the same cobalt-chromium design: an analysis of 17,577 prostheses from the Australian Orthopaedic Association National Joint Replacement Registry. J Bone Joint Surg Am 99(4):275-283

51. Heyse T, Haas SB, Efe T (2012) The use of oxidized zirconium alloy in knee arthroplasty. J Expert Rev Med Dev 9(4):409-421

52. Piconi C, De Santis V, Maccauro G (2017) Clinical outcomes of ceramicized ball heads in total hip replacement bearings: a literature review. J Appl Biomater Funct Mater 15(1):e1-e9

53. Vierra BM, Blumenthal SR, Amanatullah DF (2017) Modularity in total hip arthroplasty: benefits, risks, mechanisms, diagnosis, and management. Orthopedics 40(6):355-366

54. Hernigou P, Queinnec S, Henri C, Lachaniette F (2013) One hundred and fifty years of history of the Morse taper: from Stephen A. Morse in 1864 to complications related to modularity in hip arthroplasty. Int Orthop 37(10):2081-2088

55. Falkenberg A, Drummen P, Morlock MM, Huber G (2019) Determination of local micromotion at the stem-neck taper junction of a bi-modular total hip prosthesis design. Med Eng Phys 65:31-38

56. Urish KL, Giori NJ, Lemons JE, Mihalko WM, Hallab N (2019) Trunnion corrosion in total hip arthroplasty-basic concepts. Orthop Clin North Am 50:281-288

57. Weiser MC, Lavernia CJ (2017) Trunnionosis in total hip arthroplasty. J Bone Joint Surg Am 99:1489-1501

58. Pourzal R, Lundberg HJ, Hall DJ, Jacobs JJ (2018) What factors drive taper corrosion? J Arthrop 33(9):2707-2711 
59. Mistry JB, Chughtai M, Elmallah RK, Diedrich A, Le S, Thomas M, Mont MA (2016) Trunnionosis in total hip arthroplasty: a review. J Orthop Traumatol 17(1):1-6

60. Rodrigues DC, Urban RM, Jacobs JJ, Gilbert JL (2009) In vivo severe corrosion and hydrogen embrittlement of retrieved modular body titanium alloy hip-implants. J Biomed Mater Res B Appl Biomater 88(1):206-219

61. Weber AE, Skendzel JG, Waxman DL, Blaha JD (2013) Symptomatic aseptic hydrogen pneumarthrosis as a sign of crevice corrosion following total hip arthroplasty with a modular neck: a case report. JBJS Case Connector 3(3):e76

62. Morlock MM, Bünte D, Ettema H, Verheyen CC, Hamberg A, Gilbert J (2016) Primary hip replacement stem taper fracture due to corrosion in 3 patients. J Acta Orthop 87(2):189-192

63. Fokter SK, Rudolf R, Molicnik A (2014) Titanium alloy femoral neck fracture-clinical and metallurgical analysis in 6 cases. Acta Orthop 87(2):197-202

64. Niinomi M, Nakai M (2011) Titanium-based biomaterials for preventing stress shielding between implant devices and bone. Int J Biomater, Article ID 836587. https://doi.org/10.1155/ 2011/836587

65. Swann RP, Webb JE, Cass JR, Van Citters DW, Lewallen DG (2015) Catastrophic head-neck dissociation of a modular cementless femoral component. JBJS Case Connector 5(3):e71. https://doi.org/10.2106/JBJS.CC.N.00179

66. Urish KL, Hamlin BR, Plakseychuk AY, Levison TJ, Kurtz S, DiGioia AM (2017) Letter to the Editor on "Trunnion failure of the recalled low friction ion treatment cobalt chromium alloy femoral head." J Arthrop 32(9):2857-2863

67. Martin AJ, Jenkins DR, Van Citters DW (2018) Role of corrosion in taper failure and head disassociation in total hip arthroplasty of a single design. J Orthop Res 36(11):2996-3003

68. Matsen Ko L, Chen AF, Deirmengian GK, Hozack WJ, Sharkey PF (2016) The Journal of bone and joint surgery. American 98(16):1400-1404

69. Molloy DO, Munir S, Jack CM, Cross MB, Walter WL, Walter WK (2014) Fretting and corrosion in modular-neck total hip arthroplasty femoral stems. J Bone Joint Surg 96(6):488493

70. Walsh CP, Hubbard JC, Nessler JP, Markel DC (2015) Revision of recalled modular neck rejuvenate and ABG femoral implants. J Arthrop 30(5):822-826

71. Nawabi DH, Do HT, Ruel A, Lurie B, Elpers ME, Wright T, Potter HG, Westrich GH (2016) Comprehensive analysis of a recalled modular total hip system and recommendations for management. J Bone Joint Surg 98:40-47

72. Di Laura A, Hothi HS, Henckel J, Kwon YM, Skinner JA, Hart AJ (2018) Retrieval findings of recalled dual-taper hips. J Bone Joint Surg Am 100(19):1661-1672

73. Kurtz SM, Kocagöz SB, Hanzlik JA, Underwood RJ, Gilbert JL, MacDonald DW, Lee GW, Mont MA, Kraay MJ, Klein GR, Parvizi J (2013) Do ceramic femoral heads reduce taper fretting corrosion in hip arthroplasty? A retrieval study. Clin Orthop Relat Res 471(10):3270-3282

74. Bull SJ, Moharrami N, Langton D (2017) Mechanistic study of the wear of ceramic heads by metallic stems in modular implants. J Bio Tribo-Corrosion 3:7

75. Triantafyllopoulos GK, Elpers ME, Burket JC, Esposito CI, Padgett DE, Wright TM (2016) Otto Aufranc award: large heads do not increase damage at the head-neck taper of metal-onpolyethylene total hip arthroplasties. Clin Orthop Relat Res 474(2):330-338

76. Morlock MM (2015) The taper disaster-how could it happen? HIP Int 25(4):339-346

77. Goldberg JR, Gilbert JL (2003) In vitro corrosion testing of modular hip tapers. J Biomed Mater Res Part B Appl Biomater 64(2):78-93

78. Zachary JC, Coury JG, Cohen J (2017) Taper technology in total hip arthroplasty. JBJS Rev 5(6): 2

79. Shenhar A, Gotman I, Radin S, Ducheyne P, Gutmanas EY (2000) Titanium nitride coatings on surgical titanium alloys produced by a powder immersion reaction assisted coating method: residual stresses and fretting behavior. Surf Coat Technol 126(2-3):210-218

80. Shearwood-Porter N, Browne M, Milton JA, Cooper MJ, Palmer MR, Latham JM, Wood RJK, Cook RB (2017) Damage mechanisms at the cement-implant interface of polished cemented femoral stems. J Biomed Mater Res Part B Appl Biomater 105(7):2027-2033 
81. Choi D, Park Y, Yoon Y-S, Masri BA (2010) In vitro measurement of interface micromotion and crack in cemented total hip arthroplasty systems with different surface roughness. Clin Biomech 25:50-55

82. Zhang H, Brown LT, Blunt LA, Jiang X, Barrans SM (2009) Understanding initiation and propagation of fretting wear on the femoral stem in total hip replacement. Wear 266(5-6):566569

83. Bader R, Steinhauser E, Holzwarth U, Schmitt M, Mittelmeier W (2004) A novel method for evaluation of the abrasive wear behaviour of total hip stems at the interface between implant surface and bone cement. Proc Inst Mech Eng, Part H 218(4):223-230

84. Thomas SR, Shukla D, Latham PD (2004) Corrosion of cemented titanium femoral stems. J Bone Joint Surg (BR) 86B:974-978

85. Hallan G, Espehaug B, Furnes O, Wangen H, Hol PJ, Ellison P, Havelin LI (2012) Is there still a place for the cemented titanium femoral stem? Acta Orthop 83(1):1-6

86. Noronha Oliveira M, Schunemann WVH, Mathew MT, Henriques B, Magini RS, Teughels W, Souza JCM (2018) Can degradation products released from dental implants affect peri-implant tissues? J Periodontal Res 53:1-11

87. Cruz HV, Souza JCM, Henriques M, Rocha LA (2011) Biomedical tribology (Paulo Davim J, ed). Nova Science Publishers, Hauppauge (New York), pp 2-33

88. Corne P, De March P, Cleymand F, Geringer J (2019) Fretting-corrosion behavior on dental implant connection in human saliva. J Mech Behav Biomed Mater 94:86-92

89. Alrabeah GO, Knowles JC, Petridis H (2018) Reduction of tribocorrosion products when using the platform-switching concept. J Dent Res 97:995-1002

90. Fransson C, Wennström J, Tomasi C, Berglundh T (2009) Extent of peri-implantitis-associated bone loss. J Clin Periodontol 36:357-363

Open Access This chapter is licensed under the terms of the Creative Commons Attribution 4.0 International License (http://creativecommons.org/licenses/by/4.0/), which permits use, sharing, adaptation, distribution and reproduction in any medium or format, as long as you give appropriate credit to the original author(s) and the source, provide a link to the Creative Commons license and indicate if changes were made.

The images or other third party material in this chapter are included in the chapter's Creative Commons license, unless indicated otherwise in a credit line to the material. If material is not included in the chapter's Creative Commons license and your intended use is not permitted by statutory regulation or exceeds the permitted use, you will need to obtain permission directly from the copyright holder. 